\title{
Investigations into the possible regulation of negative gravitropic curvature in intact Avena sativa plants and in isolated stem segments by ethylene and gibberellins
}

\author{
Peter Kaufman, Richard P. Pharis, David M. Reid and Frederick D. Beall
}

Kaufman, P., Pharis, R. P., Reid, D. M., and Beall, F. D. 1985. Investigations into the possible regulation of negative gravitropic curvature in intact Avena sativa plants and in isolated stem segments by ethylene and gibberellins. - Physiol. Plant. 65: 237244.

Using Avera sativa L. cv. Victory oat seedlings and excised p-1 stem segments (including the $\mathrm{p}-1$ and $\mathrm{p}-2$ internodes) the effect of exogenously supplied ethylene and the removal of ethylene on internodal extension and gravitropic bending was assessed. Similarly, the ability of the excised system to respond to gravistimulation was assessed in the presence of inhibitors of ethyleme action $\left(\mathrm{AgNO}_{3}\right)$ and ethylene synthesis (3,5-diiodo-4-hydroxybenzoic acid and benzyl isothiocyanate; BITC). The production of ethylene from both intact and excised systems was also measured from 0 to 48 h after gravistimulation, relative to vertical controls.

Although gravitropic curvature is initiated, and indeed enters the most rapid phase of upward bending during the first $6 \mathrm{~h}$, there is no difference in ethylene production between vertical and geostimulated plants during this period. The ethylene production of gravistimulated plants rises sharply to a maximum at $24 \mathrm{~h}$, then decreases steeply to almost the control level by $48 \mathrm{~h}$, at which time the rate of upward curvature is diminishing. Nether the addition nor removal of ethylene, nor the addition of indibitors affecting ethylene-action $\left(\mathrm{AgNO} \mathrm{NO}_{3}\right)$ or synthesis (DIHB) influence gravitropic bending or internodal extension in excised segments. Although the ethylene synthesis inhibitor BITC slowed down the rate of upward bending, this effect could not be reversed by addition of ethylene. We conclide that the burst in ethyleme production that develops in leaf-sheath bases (pulvini) after they have started to curve upwards is not primary to the induction of curvature. We further suggest that ethylene has no major effect or role in the induction of upward bending after gravistimulation.

The metabolism of high specific activity gibberellin $A_{1}\left([H]-G A_{1}\right)$ in the excised system was assessed during 1,2 and $4 \mathrm{~h}$ of gravistimulation. Changes in endogenous $\mathrm{GAs}$ and $\mathrm{GA}$ metabolism have been shown previously to be correlated (at the later stages) with gravistimulated bending in intact Avena shoots. The excised segments "leaked" free [ $\left.{ }^{3} \mathrm{H}\right]-\mathrm{GAs}$ and $\left[{ }^{3} \mathbf{H}\right]-\mathrm{GA}$ glucosyl conjugate-like substances into the bathing medium, and this was a confonnding factor. Nevertheless, gravistimulated stem segments, and especially the bottom half of the segment, were significantly less leaky then vertical segments. Thus, just $1 \mathrm{~h}$ after gravistimulation, bottom segment halves retained $22 \%$ more precursor $\left[{ }^{3} \mathrm{H}\right]-\mathrm{GA}_{1}, 36 \%$ more free $\left[{ }^{3} \mathrm{H}\right]$-GA-like metabolites, and $48 \%$ more $\left[{ }^{3} \mathrm{H}\right]$-GA glucosyl conjugate-like metabolites than vertical segments. In contrast, the $1 \mathrm{~h}$ gravistimulated top halves retained slightly less (1-4\%) precursor $\left[{ }^{3} \mathrm{H}\right]-\mathrm{GA}$ and free $\left[{ }^{3} \mathrm{H}\right]-\mathrm{GA}$ metabolites, but $21 \%$ more $\left[{ }^{3} \mathrm{H}\right]-\mathrm{GA}$ glucosyl conjugate-like radioactivity than vertical segments.

Additional key words - Gibberellin metabolites, gravistimulation., pulvinus, transduction phase, $\left[{ }^{3} \mathrm{H}\right] \mathrm{GA}$.

Peter B. Kaufman, Dept of Cellular and Molecular Biology, Division of Biological Sciences, Uniw of Michigan, Ann Arbor, Michigan 48I09, U.S.A., R. P. Pharis (reprint requests), D. $M$. Reid, and $F$. D. Beall, Plant Physiology Research Group, Biology Dept, Univ of Calgary, Calgary, Alberta T2N 1N4, Canada.

Received 8 February, 1985; revised 17 June, 1985 


\section{Introduction}

The regulation of the transduction process by hormones during gravitropic curvature in shoots of cereals has largelly focussed on the role that free IAA (indole-3-acetic acid) and its conjugates ( $m y o$-inositol ester of IAA and amide-linked IAA) play in the asymmetric growth response (Kaufman et al. 1979, Bandurski et al. 1984). Changes in levels and metabolism of gibberellins (GAs) and their conjugates also appear to be involved in the regulation of the gravitropic curvature response in cereal shoots (Kaufman et al. 1976, Pharis et al. 1981). In the latter study, it was shown that gravistimulation results in the increased accumulation of conjugate-like substances of $\left[{ }^{3} \mathrm{H}\right]-\mathrm{GA}_{4}$ and its metabolites in the upper halves, whereas free $\left.{ }^{3} \mathrm{H}\right]-\mathrm{GA}_{4}$ and its free $\mathrm{GA}$ metabolites, as well as endogenous GA-like substances, increased in the lower halves of the graviresponsive leafsheath and internodal pulvini during the initial $30^{\circ}$ of negative gravitropic curvature.

Ethylene has been suggested to be a regulator of gravitropic curvature in lodged (gravistimulated) grass shoots and in gymnosperm and dicotyledonous shoots (Blake et al. 1980, Bucher and Pilet 1981, Salisbury and Wheeler 1981, Wheeler and Salisbury 1981, Wright et al. 1978), but its role in this response is controversial (Clifford et al. 1983).

Because of the controversy surrounding ethylene's purported role in the gravitropic curvature response, we set out to investigate the role, if any, ethylene has in regulating negative gravitropic curvature in leaf-sheath pulvini in oat (Avena) shoots in excised stem segments and in intact plants. Likewise, because we (Pharis et al. 1981) had worked with the intact oat plant, vis a vis analysis of endogenous GA-like substances and metabolism of [ $\left.{ }^{3} \mathrm{H}\right]-\mathrm{GA}_{4}$, at only one, and rather late, stage of gravitropic bending (namely, at $24 \mathrm{~h}$, when curvature has reached $30^{\circ}$ ), we have extended our analysis with the excised stem segments to include changes in $\left[{ }^{3} \mathrm{H}\right]$ $\mathrm{GA}_{1}$ and $\left[{ }_{3} \mathrm{H}\right]-\mathrm{GA}_{4}$ metabolism, and changes in their relative distribution within the pulvinus. Gibberellins $A_{1}$ and $\mathrm{A}_{4}$ are both native to Avena (Noma, M., Abe, H., Pharis, R., and Kaufman, P., unpublished results). These changes were followed during earlier stages of the gravitropic curvature response from the time just after bending is initiated ( 15 to $20 \mathrm{~min}$ after initiation of gravistimulation treatment) to the time it has entered the $\log$ phase of curvature (e.g. during the first $4 \mathrm{~h}$ ). It was hoped that these comparisons would allow us to answer the questions: Are early changes in the distribution of these native GAs of Avena in the lower and upper halves of gravistimulated leaf-sheath pulvini the same as seen at later stages of gravitropic bending [e.g. $30^{\circ}$ (Pharis et al. 1981)], and can one correlate changes in $\left[{ }^{3} \mathrm{H}\right]-\mathrm{GA}$ metabolites in gravistimulated shoots with the earliest stages of gravitropic bending?
Abbreviations - $\mathrm{AgNO}_{3}$, silver nitrate; $\mathrm{BITC}$, benzyl isothiocyanate; DIHB, 3,5-diiodo-4-hydroxybenzoic acid; GA, gibberellin; IAA, indole-3-acetic acid.

\section{Materials and methods}

\section{Growth of oat plants}

Plant material of Avena sativa L. cv. Victory (from Svenska Allmänna A.B., Svalöf, Sweden) was grown in Calgary and used for experiments with ethylene at a stage when next-to-last internodes were entering $\log$ phase of extension (plants 42 to 45 days old) and for experiments with $\left[{ }^{3} \mathrm{H}\right]-\mathrm{GA}_{4}$ and $\left[{ }^{3} \mathrm{H}\right]-\mathrm{GA}_{1}$, when plants were 21 days old. For the ethylene experiments, plants were grown in pots or flats in a cooled greenhouse maintained at $23^{\circ} \mathrm{C}$ under natural photoperiod from May to August. For experiments with radioactive GAs, plants were grown in a growth chamber programmed for $16 \mathrm{~h}$ photoperiods and a $23^{\circ} \mathrm{C}$ temperature regime. Irradiation ( 400 to $700 \mathrm{~nm}$ ) was measured with a LI-COR LI1925 quantum sensor and was $248 \mu \mathrm{mol} \mathrm{m} \mathrm{m}^{-2} \mathrm{~s}^{-4}$.

\section{Ethylene experiments with excised oat stem segments}

For measurements of ethylene production during gravitropic bending, we used 2-cm stem segments that included the top of the p-2 internode (second from last internode below the peduncle of the inflorescence), the sheath base and leaf-sheath pulvinus from the $p-1$ node (node just below peduncular node of the inflorescence), and the enclosed basal portion of the p- 1 internode (first internode below the peduncle of the inflorescence) (Fig. $1 \mathrm{~A}$ and $\mathrm{B}$ ). Excised stem segments were aligned in rows under a stack of three standard-sized microscope slides with the pulvini positioned just beyond the stack of slides (Fig. 2A). The segments were lying on a $0.6-\mathrm{cm}$ disk of filter paper saturated with $0.1 \mathrm{M}$ sucrose in a 9.6- $\mathrm{cm}$ Petri dish. Another Petri dish base was inverted and placed over the bottom dish and sealed with stopcock grease. Ethylene was supplied to these chambers by slightly opening the two Petri dishes and injecting the appropriate quantity of $1000 \mathrm{ppm}$ ethylene, then resealing the dishes with silicone high vacuum grease. The ethylene standard was obtained from Applied Research Labs (State College, Penn., U.S.A.). Measurement of ethylene concentration in the chambers $1 \mathrm{~h}$ after this procedure showed that we were able to obtain the desired ethylene concentration within $\pm 3 \% . \mathrm{HgClO}_{4}$ was used as a sink for endogenously produced ethylene by inserting a vial containing $5 \mathrm{ml} \mathrm{HgClO}_{4}(0.25 M)$ into each set of sealed Petri dishes. The vials were $2 \times 1 \times 1$ $\mathrm{cm}$ in size and each contained a $\mathrm{HgClO}_{4}$-saturated filter paper wick protruding above it to aid in trapping the ethylene. All experiments with exogenously applied ethylene, or with $\mathrm{HgClO}_{4}$ traps, were repeated at least three times. 


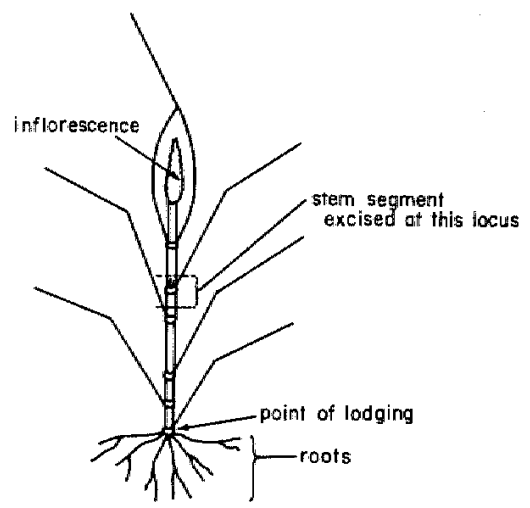

A

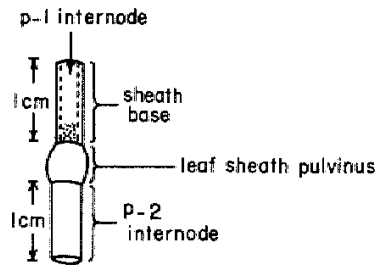

B

Fig. 1. A, Diagrammatic representation of the intact oat plant at the time of lodging (e.g., gravistimulation) and/or excision of stem segment. B, Diagrammatic representation of the excised aat stem segment.

\section{Ethylene experiments with intact oat plants}

For these experiments, we grew 8 to 10 oat plants in each of $15 \mathrm{~cm}$ diameter pots to age 42 to 45 days. In order to supply exogenous ethylene and to trap endogenously produced ethylene, we placed wire supports over the plants, covered this frame with 121 polyethylene bags, and sealed the bags around the pot rims with rubber bands. We used six pots of plants per treatment. Ethylene treatments were made by injecting the appropriate quantity of $1000 \mathrm{ppm}$ standard ethylene gas into each plastic bag. When we wished to scrub endogenously produced ethylene, we used a trap consisting of two vials of $\mathrm{HgClO}_{4}(5 \mathrm{ml})$, accompanied with protruding filter paper wicks saturated with $\mathrm{HgClO}_{4}$, into each bag. The plants in the bagged pots were either left upright or placed horizontally (plants gravistimulated) after treatment. During treatment they were placed in a controlled environment chamber (Conviron Co. Ltd., Winnipeg) at $16-\mathrm{h}$ photoperiods, $23^{\circ} \mathrm{C}$ days, $18^{\circ} \mathrm{C}$ nights, and $85 \%$ relative humidity. Air samples in the plastic-bagged pots were taken at time zero of treatment, and at 24 and $48 \mathrm{~b}$ after treatments were initiated, in order to measure ethylene production lexpressed as $\mu$ ethylene ( $g$ fresh weight tissue $\left.)^{-1}\right]$. Gravitropic curvature response in the leaf-sheath pulvini was also measured at each time of air sampling.

\section{Inhibition of ethyleme syothesis}

The inhibitors used were benzyl isothiocyanate (BITC) (Patil and Tang 1974) and 3,5-diiodo-4-hydroxybenzoic acid (DIHB) (Robert et al. 1975). Silver nitrate $(\mathrm{AgNO})_{3}$ was employed as the inhibitor of ethylene ac tion (Beyer 1976).

\section{Ethylene production}

At different times after treatments, leaf-sheath pulvini were excised from either stem segments or from intact plants that had been left upright or gravistimulated. The pulvini were packed into small glass vials $(1 \mathrm{ml}$ capacity, Pierce Chemical Company) and sealed with rubber $\mathrm{GC}$ septa. Three $10 \mathrm{ml}$ capacity syringes were inserted into each vial with the plungers extended to full capacity to create a wacuum in the vials and thus expel endogenously produced ethylene from the tissue. This was done for $4 \mathrm{~min}$, then the plungers released. One $\mathrm{ml}$ gas samples were taken from the vials and injected into a gas chromatograph (Varian GC Model 3700) with a Porapak Q, 80 to 100 mesh column (Waters Associates). The $\mathrm{GC}$ was held at injector temperature, $70^{\circ} \mathrm{C}$; oven temperature, $70^{\circ} \mathrm{C}$; and the flame ionization detector at $120^{\circ} \mathrm{C}$. Carrier gas was nitrogen with a flow rate of $30 \mathrm{ml}$ min $^{-1}$. All ethylene determinations were repeated at least three times.

\section{Radioactive [ $\left.{ }^{3} \mathrm{H}\right]-\mathrm{GA} \mathrm{A}_{1}$ and $\left[{ }^{3} \mathrm{H}\right]-\mathrm{GA}_{4}$ feeds}

The experimental set-up is depicted in Fig. 2B. The excised shoots were from 19 -day-old oat plants. The basic treatments included: $0.1 \mathrm{M}$ sucrose (control), $0.1 \mathrm{M}$ sucrose plus $\left[{ }^{3} \mathrm{H}\right]-\mathrm{G}_{\mathrm{A}}$, and $0.1 M$ sucrose plus $\left[{ }^{3} \mathrm{H}\right]-\mathrm{G}_{4}$.

Distribution of radioactivity $(\mathrm{Bq})$ extracted from top, bottom and left plus right halves (data averaged for vertical halves in statistical comparisons with gravistimulated halves) of gravistimulated and upright excised stem segments, respectively, containing node-pulvini (Fig. 1B) of Awena, was examined 1, 2 and $4 \mathrm{~h}$ after excision from the shoot. Twenty shoots for each of the gravistimulation treatments and ten shoots from each of the upright treatments were cut just below the p-1 nodepulvinus and stood upright in $2 \mathrm{ml}$ of $0.1 \mathrm{M}$ sucrose solution with $166 \times 10^{3} \mathrm{dpm}\left[{ }^{3} \mathrm{H}\right]-\mathrm{GA}_{4}$ (specific activity = $44.4 \mathrm{GBq} \mathrm{mmol}^{-1}$ ) or $140 \times 10^{3} \mathrm{dpm}\left[{ }^{3} \mathrm{H}\right]-\mathrm{GA}_{1}$ (specific activity $\left.>370 \mathrm{GBq} \mathrm{mmol}^{-1}\right)$ for $24 \mathrm{~h}$ (11 h light, $8 \mathrm{~h}$ dark, $5 \mathrm{~h}$ light). Then node-pulvinus stem segments (Figs $1 B$ and 2B) were excised from these shoots and incubated in $0.1 \mathrm{M}$ sucrose solution for each of 1,2 and 4 h (giwing, respectively, $0^{\circ}, 0.75^{\circ}$ and $2.5^{\circ}$ curvature when shoots were gravistimulated) in either an upright (10 segments) or horizontal (20 segments) position. All 
node-pulvinus stem segments were cut in half at time of harvest, the vertical halves being extracted as 10 "left" and 10 "right" halves, the horizontal halves being extracted in groups of 20 lower or 20 upper halves. The $80 \%$ methanolic extract was taken to dryness and chromatographed directly on a $n$-hexane ethyl acetate gradient-eluted $\mathrm{SiO}_{2}$ partition column (Durley et al. 1972), the highly water-soluble radioactivity [which will contain GA glucosyl conjugates (see Koshioka et al. 1983)] being removed at the very last by washing the $\mathrm{SiO}_{2}$ with $100 \mathrm{ml}$ of absolute methanol. In the terminology used hereafter "precursor" constitutes the discrete peak, eluting at the same retention time as authentic $\left[{ }^{3} \mathrm{H}\right]-\mathrm{GA}_{1}$ or $\left[{ }^{3} \mathrm{H}\right]-\mathrm{GA}_{4}$, as the case may be. "Major free GA metabolites" constitute all other peaks eluting from the column prior to the "methanol wash", and "highly water soluble" constitute all radioactivity eluted finally with absolute methanol.

Using the signed rank test (Snedecor and Cochran, 1967) comparisons (e.g., a comparison of upright versus the mean of top + bottom, and of top versus bottom) were made for each of "precursor", major free acid metabolites", "highly water soluble", and "total radioactivity" categories over all times and experiments. A one-way analysis of variance was also performed on the mean of uprights, tops and bottoms, at the 1,2 and $4 \mathrm{~h}$ harvests for each of the precursors, free GA metabolites and highly $\mathrm{H}_{2} \mathrm{O}$ soluble metabolites (e.g., GA glucosyl conjugate-like substances).

\section{Results and discussion}

\section{Ethylene experiments with excised stem segments}

The purpose of these experiments was to assess the effects of exogenous ethylene, of scrubbing endogenous ethylene, and of inhibitors of ethylene synthesis and action on internodal extension and gravitropic bending (Fig. 2A). From Tab. 1, it is obvious that exogenous ethylene, the scrubbing of endogenously-produced eth-

Tab. 1. Effect of exogenously supplied ethylene, of scrubbing endogenously produced ethylene ( $\mathrm{HgClO}_{4}$ trap), and of an inhibitor of ethylene action $\left(\mathrm{AgNO}_{3}\right)$ on gravitropic bending and internodal extension in excised oat stern segments. All segments were incubated in $0.1 \mathrm{M}$ stucrose for $24 \mathrm{~h}$ in the dark at $25^{\circ} \mathrm{C}$. Twenty-four segments were used for each treatment.

\begin{tabular}{|c|c|c|}
\hline Treatment & $\begin{array}{l}\text { Curvature } \\
\text { (degrees) }\end{array}$ & $\begin{array}{l}\text { Length of } \\
\text { internode } \\
\text { portion that } \\
\text { extends from } \\
\text { sheath (mm) }\end{array}$ \\
\hline Control $(0.1 \cdot M$ sucrose $)$ & $27.60 \pm 0.82$ & $10.58 \pm 0.12$ \\
\hline Ethylene, $100 \mu \mathrm{ll}^{-1}$ for $2 \mathrm{~h}$ & $28.00 \pm 1.60$ & - \\
\hline Ethylene, $100 \mu \mathrm{I} \mathrm{I}^{-1}$ for $24 \mathrm{~h}$ & $26.39 \pm 0.85$ & $10.39 \pm 0.20$ \\
\hline Ethylene, $500 \mathrm{ul} \mathrm{l}^{-1}$ for $24 \mathrm{~h}$ & $28.17 \pm 1.01$ & $10.81 \pm 0.17$ \\
\hline $\mathrm{AgNO}_{3}, 5 \mathrm{mg} \mathrm{i}^{-1}$ for $24 \mathrm{~h}$ & $28.10 \pm 2.26$ & - \\
\hline $\mathrm{HgClO}_{4}$ ethylene trap for $24 \mathrm{~h}$ & $28.03 \pm 0.92$ & $10.69 \pm 0.18$ \\
\hline
\end{tabular}

Tab. 2. Effect of the addition of an ethylene synthesis inhibitor (DIHB) and of an ethylene action inhibitor $\left(\mathrm{AgNO}_{3}\right)$ on gravitropic bending, internodal extersion, and ethyleme production in the oat stem segment bioassay system. All segments were incubated in $0.1 \mathrm{M}$ sucrose \pm inhibitor at $25^{\circ} \mathrm{C}$ in the dark. Twenty-four stem segments were used for each treatment.

\begin{tabular}{|c|c|c|c|}
\hline $\begin{array}{l}\text { Treatments and } \\
\text { respective } \\
\text { incubation times }\end{array}$ & $\begin{array}{l}\text { Curvature } \\
\text { (degrees) }\end{array}$ & $\begin{array}{l}\text { Length of } \\
\text { internode } \\
\text { portion that } \\
\text { extends from } \\
\text { sheath (mm) }\end{array}$ & $\begin{array}{c}\text { Ethylene } \\
\text { produced } \\
{\left[\mathrm{nl}(\mathrm{gFW})^{-1}\right]}\end{array}$ \\
\hline Control, $0 \mathrm{~h}$ & $1.9 \pm 0.2$ & - & 0.408 \\
\hline Control, $5 \mathrm{~h}$ & $5.5 \pm 0.4$ & - & 0.308 \\
\hline $\begin{array}{l}\text { DIHB, } 50 \mu M, 5 \mathrm{~h} \\
\mathrm{AgNO}_{3}, 5 \mathrm{mg} 1^{-1}\end{array}$ & $5.9 \pm 0.5$ & - & 0.308 \\
\hline $5 \mathrm{~h}$ & $4.4+0.5$ & - & 0.179 \\
\hline \multirow{3}{*}{$\begin{array}{l}\text { Control, } 24 \mathrm{~h} \\
\text { DHHB, } 50 \mu M, 24 \mathrm{~h} \\
\mathrm{AgNO}_{3}, 5 \mathrm{mg} \mathrm{I}^{-1}, \\
24 \mathrm{~h}\end{array}$} & $21.6 \pm 1.0$ & $15.6 \pm 0.6$ & 0.855 \\
\hline & $29.8 \pm 1.3$ & $16.3 \pm 1.0$ & 0.763 \\
\hline & $21.1 \pm 1.4$ & $14.3 \pm 1.0$ & 0.277 \\
\hline
\end{tabular}

ylene, or the inhibiting of ethylene action with $\mathrm{AgNO}_{3}$, did not affect gravitropic bending or internodal extension in these segments. Results in Tab. 2 indicate (1)

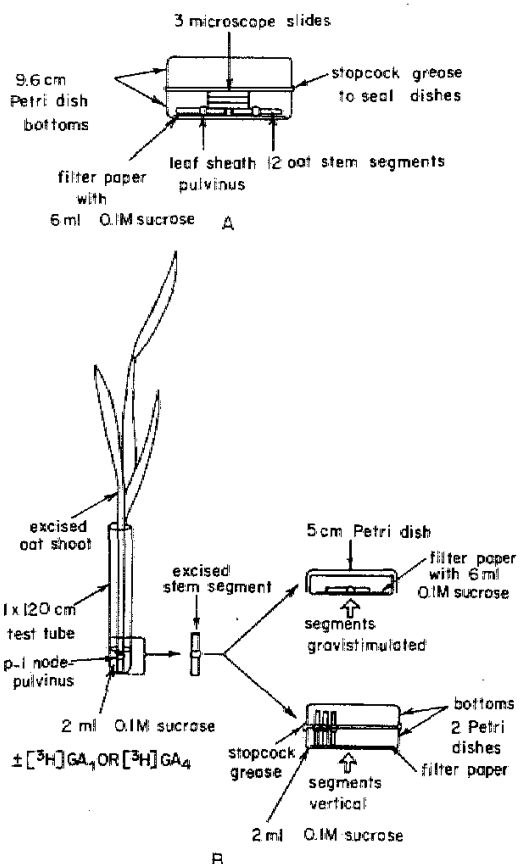

Fig. 2. A, Diagrammatic representation of the chamber used to measure ethylene evollution, or to modify the gaseous environment of exised oat stem segments, or used to apply various inhibitors in solution. B, Diagrammatic representation of the excised oat shoot (on left) to which $\left[{ }^{3} \mathrm{H}\right]-\mathrm{GA}$, or $\left[{ }^{3} \mathrm{H}\right]-\mathrm{GA}_{4}$ was administered for 24 th prior to excision and treatment (on right). 


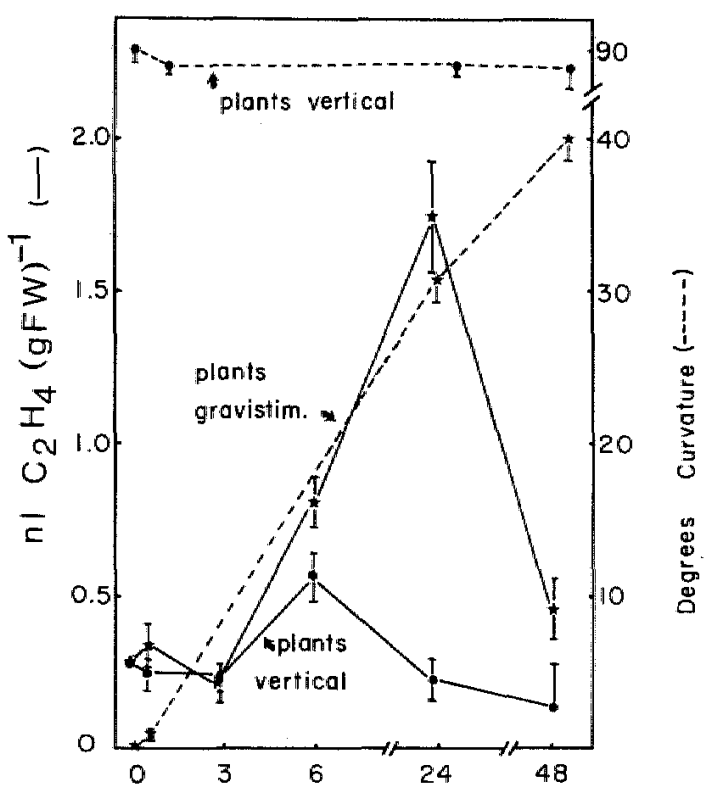

Time After Gravistimulation

(hours)

Fig. 3. Comparison of kinetics of curvature after gravistimulation treatment and time-course of ethylene evolution from vertical and gravistimulated intact oat plants over a 48 -h period.

that neither the ethylene synthesis inhibitor, DIHB, nor the ethylene action inhibitor, $\mathrm{AgNO}_{3}$, repress or inhibit gravitropic curvature or internodal extension, and (2) that endogenous ethylene production is only slightly lowered at 24 h by DIHB, but more significantly lowered by $\mathrm{AgNO}_{3}$. Another ethylene synthesis inhibitor, BITC, at $46 \mu \mathrm{M}$, slows down the rate of upward bending (control $=27.6^{\circ} \pm 0.82^{\circ}$ and $\mathrm{BITC}=16.6^{\circ} \pm 0.78^{\circ}$ at 24 h), but at no time could we get exogenous ethylene to reverse these effects. This suggests that BITC may be having an effect on bending that is unrelated to an influence on ethylene production.

\section{Ethylene experiments with intact plants}

Figure 3 shows the time-course for curvature in gravistimulated intact plants. Based on measurements with an angular recording transducer, the upward bending in gravistimulated oat plants begins after about $30 \mathrm{~min}$ of gravistimulation (Kaufman and Dayanandan 1984). The most rapid phase of upward bending is reached within one hour (Fig. 3). Between one and $24 \mathrm{~h}$, the rate of bending is about $3.3^{\circ}$ per $\mathrm{h}$. This rate diminishes after 24 $\mathrm{h}$, and by $72 \mathrm{~h}$ (data not shown), the response has ceased. This upward curvature response in intact, lodged (gravistimulated) oat plants results from a bending response that occurs in at least three leaf-sheath pul- vini on each shoot. Thus, the gravitropic curvature data presented in Fig. 3 are based on the sum of angles achieved for all of the graviresponding pulvini on a given shoot at each particular time of measurement.

The long-term kinetics ( 0 to $48 \mathrm{~h}$ ) for ethylene production in pulvini excised from these shoots at different times are also traced in Fig. 3, and the fine kinetics ( 0 to $6 \mathrm{~h})$ for ethylene production are shown in Fig. 4 . There is no significant difference in ethylene production in pulvini derived from vertical shoots as compared with those obtained from the prostrated shoots during the first $6 \mathrm{~h}$ (Fig. 4). It is during this time period that gravitropic curvature has been initiated and enters the most rapid phase of upward bending. In contrast, during the period between 6 and $24 \mathrm{~h}$ the rate of ethylene release from the tissue increases steeply. Maximum ethylene release is obtained at $24 \mathrm{~h}$, after which time it decreases steeply and reaches almost the control level by $48 \mathrm{~h}$. This period, when ethylene is decreasing in the pulvini, closely parallels the period when the rate of upward curvature is diminishing.

Assuming that ethylene can diffuse rapidly and freely out of the tissue and that the ethylene inhibitors are blocking ethylene synthesis and action, we feel that the burst in ethylene production that develops in pulvini after they have started to curve upwards is not primary to the induction of curvature in the pulvini, but rather, may be the result of gravistimulation-induced stress. It is also possible that the burst in ethylene may be caused by the elevated levels of free IAA that occur in the pulvini by $24 \mathrm{~h}$ (seven times more free IAA occurs in gravistimulated pulvini than in vertical pulvini), especially on the lower halves, where asymmetric curvature is greatest (almost three times more free IAA in the lower halves than in the upper halves) (Kaufman et al. 1979, Kaufnan and Dayanandan 1984, Wright et al. 1978).

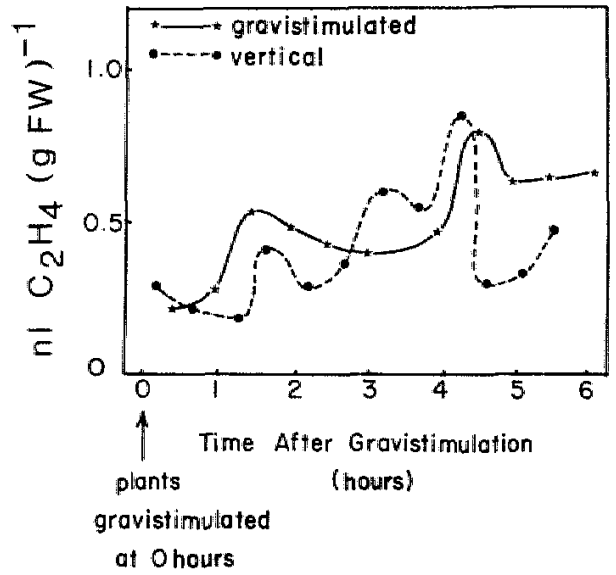

Fig. 4. Early kinetics ( $0-6$ h) of ethylene evolution for gravistimulated oat stem segments relative to vertical stem segments (techniques same as per Fig. 2A). 
However, even though the elevated levels of ethylene appear after gravitropic curvature is initiated, it is possible that this enhanced ethylene production in the graviresponding pulvini could be responsible for the decrease in rate of curvature that occurs just following the peak in ethylene production (Fig. 3; and Clifford et al. 1983). Huxter et al. (1979) observed a similar situation with regard to the growth of tobacco callus. There, alterations in growth rate first led to increased ethylene production, the extra ethylene appearing to subsequently reduce growth rate.

It should be noted that in no case could we alter the gravitropic curvature response in intact oat plants by adding exogenous ethylene to gravistimulated plants. This inefficacy of exogenous ethylene might be explained by the fact that the high levels of endogenous ethylene that are produced as a consequence of gravistimulation saturate the system with ethylene. However, such a method of application of exogenous ethylene will not result in an assymetrical distribution of ethylene inside the tissue. Nevertheless, we tried an ethylene trap by inserting vials of $\mathrm{HgClO}_{4}$ into the environment of the bagged plants; this also had no effect on the initial gravitropic curvature response.

Ethylene production and release is enhanced by gravistimulation of cereal shoots, as shown by Wright et al. (1978) and the results presented here (Fig. 3). The question we pose: Is this enhanced ethylene production of importance in the induction of upward bending in gravistimulated cereal grass shoots? Or, is it merely a result of gravitropic curvature, and thus, of possible regulatory significance only at later stages during gravitropic bending? Our results (Figs 3 and 4) indicate that the elevated ethylene production and release occur well after gravistimulated shoots start to bend upwards (ca $5.5 \mathrm{~h}$ later). Thus, the enhancement in ethylene release may occur as a result of the stress induced by gravistimulation.

Since we do obtain enhanced ethylene levels in graviresponding oat shoots, what role, if any, might ethylene play in this response? Experiments with inhibitors of ethylene synthesis and ethylene action shown (Tabs 1 and 2) for excised oat stem segments suggest that these compounds do not elicit any significant diminution in the amount of gravitropic curvature over $24 \mathrm{~h}$. Nor does the use of a $\mathrm{HgClO}_{4}$ trap inhibit or repress the upward bending response. The only other conclusion that we can reach is that ethylene might be responsible for triggering the diminution in rate of bending that occurs between 24 and $72 \mathrm{~h}$ in intact oat plants, a conclusion similar to that reached by Clifford et al. (1983). This seems reasonable for oats in the light of the massive peak in ethylene production that occurs between 6 and $24 \mathrm{~h}$, before bending rate begins to slow down.

\section{$\left[{ }^{3} \mathrm{H}\right]-$ Gibberellin feed experiment}

From the feeding experiment with $\left[{ }^{3} \mathrm{H}\right]-\mathrm{GA}_{1}$ and $\left[{ }^{3} \mathrm{H}\right]$ -
Tab. 3. Comparison of radioactivity $(\mathrm{Bq})$ in precursor $\left(\left[{ }^{3} \mathrm{H}\right]\right.$ $\mathrm{GA}_{1}$ ), free [ $\left.{ }^{3} \mathrm{H}\right]-\mathrm{GA}$-like metabolites and highly water-soluble metabolites $\left(\left[^{3} H\right]-G A\right.$ glucosyl conjugate-like), in upright stem segments (pooled halves divided by 2) as compared with top and bottom halves of gravistinuulated stem segments. $\left[{ }^{3} \mathrm{H}\right]-\mathrm{GA}_{3}$ was ardministered to vertical shoots for $24 \mathrm{~h}$ prior to excision of the $p-1$ and $p-2$ internodes (including $p-1$ node pulvinus). The stem segments were gravistimulated for 1,2 or $4 \mathrm{~h}$ prior to harvest and halving. See Results and discussion for further details on statistical significance and on a similar comparison using $\left[{ }^{3} \mathrm{H}\right]-\mathrm{GA}_{4}$.

\begin{tabular}{|c|c|c|c|c|}
\hline \multirow[t]{2}{*}{$\begin{array}{l}\mathrm{SiO}_{2} \text { partition } \\
\text { fraction grouping }\end{array}$} & \multirow[t]{2}{*}{$\begin{array}{l}\text { Segment } \\
\text { position }\end{array}$} & \multicolumn{3}{|c|}{$\begin{array}{c}{\left[{ }^{3} \mathrm{H}\right]-\mathrm{G} \mathrm{A}_{1} \text { feed }} \\
\text { harvest time }\end{array}$} \\
\hline & & $1 \mathrm{~h}$ & $2 \mathrm{~h}$ & $4 \mathrm{~h}$ \\
\hline \multirow{3}{*}{$\begin{array}{l}\text { Precursor } \\
{\left[{ }^{3} \mathrm{H}\right]-\mathrm{GA}_{1}}\end{array}$} & Upright $1 / 2$ & 404 & 205 & 312 \\
\hline & Top $1 / 2$ & 399 & 294 & 424 \\
\hline & Bottom $1 / 2$ & 494 & 240 & 356 \\
\hline \multirow{3}{*}{$\begin{array}{l}\text { Major free }\left[{ }^{3} \mathrm{H}\right] \text { - } \\
\text { GA-like metabolites }\end{array}$} & Upright $1 / 2$ & 94 & 73 & 77 \\
\hline & Top $1 / 2$ & 90 & 70 & 104 \\
\hline & Bottom $1 / 2$ & 127 & 62 & 100 \\
\hline \multirow{2}{*}{\multicolumn{5}{|c|}{$\begin{array}{l}\text { Highly } \mathrm{H}_{2} \mathrm{O} \\
\left.\text { soluble [ }{ }^{3} \mathrm{H}\right]-\end{array}$}} \\
\hline & Upright $1 / 2$ & 745 & 875 & 935 \\
\hline \multirow{2}{*}{$\begin{array}{c}\left(\left[{ }^{3} \mathrm{H}\right]-\mathrm{GA} \text { glucosyl }\right. \\
\text { conjugate-like })\end{array}$} & Top $1 / 2$ & 902 & 962 & 1086 \\
\hline & Bottom $1 / 2$ & 1086 & 915 & 1020 \\
\hline \multirow[t]{3}{*}{ Total $\left[{ }^{3} \mathrm{H}\right]$-metabolites } & Upright $1 / 2$ & 824 & 949 & 1019 \\
\hline & Top $1 / 2$ & 999 & 1032 & 1189 \\
\hline & Bottom $1 / 2$ & 1214 & 979 & 1126 \\
\hline \multirow[t]{3}{*}{ Total radioactivity } & Upright $1 / 2$ & 1232 & 1154 & 1331 \\
\hline & Top $1 / 2$ & 1389 & 1326 & 1613 \\
\hline & Bottom $1 / 2$ & 1708 & 1219 & 1481 \\
\hline
\end{tabular}

$\mathrm{GA}_{4}$, the following observations can be made: (1) excised segments from both upright, as well as gravistimulated, treatments proved to be leaky during the 4 -h gravistimulation period; (2) based on the radioactivity data (shown for $\left[{ }^{3} \mathrm{H}\right]-\mathrm{GA}$ feeds only, Tab. 3), gravistimulated segments were less leaky than upright segments; (3) after 1 b of gravistimulation bottom halves leaked less than either top halves or vertical halves: (4) the top halves of gravistimulated segments from plants fed $\left.{ }^{3} \mathrm{H}\right]-\mathrm{GA}_{1}$ leaked less (at 2 and $\mathbf{4} \mathrm{h}$ of gravistimulation) than the bottom halves (but they of course tend to be slightly above the liquid surface). Data for $\left[{ }^{3} \mathrm{H}\right]-\mathrm{GA}_{4}$ feeds are not shown because of the high variability between harvest times and metabolite fraction, but they can be summarized as follows: (1) Production of [ $\left.{ }^{3} \mathrm{H}\right]-\mathrm{GA}$ glucosyl conjugate-like substances during the $24 \mathrm{~h}$ incubation period was very high (in excess of $80 \%$ of extractable radioactivity) in comparison with $\left[{ }^{3} \mathrm{H}\right]-$ $\mathrm{GA}_{1}$ feeds (55-65\%). (2) Although gravistimulated segments did retain more radioactivity than vertical segments at several harvest times and for each of the precursors, free [ $\left.{ }^{3} \mathrm{H}\right]-\mathrm{GA}$-like metabolite and highly watersoluble- $\left[{ }^{3} \mathrm{H}\right]$-metabolite fractions, there were also harvest times when extractable radioactivity in the various fractions was equal to, or somewhat less in gravisti- 
mulated halves, than in vertical halves. Reasons for the inconsistent results with $\left[{ }^{3} \mathrm{H}\right]-\mathrm{GA}_{4}$, relative to $\left[{ }^{3} \mathrm{H}\right]-\mathrm{GA}_{1}$, may relate (1) to the high level of preformed conjugatelike substances, (2) to the possibility that the monohydroxylated $\mathrm{GA}_{4}$ is not only absorbed more readily ( $40-$ $60 \%$ ) than the dihydroxylated $\left[{ }^{3} \mathrm{H}\right]-\mathrm{GA}_{1}$, but it may also be more mobile within the segment, and (3) if $\mathrm{GA}_{4}$ is not active per se, whereas $\mathrm{GA}_{1}$ is active per se, then trends in localization and/or retention, if they are related to biological activity, may be seen only for $\left[{ }^{3} \mathrm{H}\right]$ $\mathrm{GA}_{1}$ and/or its metabolites.

Thus, gravistimulation of $\left[{ }^{3} \mathrm{H}\right]-\mathrm{GA}_{1}$-fed plants resulted in significantly less leakage of total radioactivity from bottom halves than top halves at hour one, and less leakage from top halves than upright halves over all times. For upright vs top + bottom halves, there were significant differences for the $\left[{ }^{3} \mathrm{H}\right]-\mathrm{GA}_{1}$ precursor $(P$ $\leq 0.01)$, free $\left[{ }^{3} \mathrm{H}\right]$-GA-like metabolites $(P \leq 0.05)$, and $\left[{ }^{3} \mathrm{H}\right]-\mathrm{GA}$ glucosyl conjugate-like metabolites $(P \leq 0.01)$, at 1,2 and 4 h harvests by one-way analysis of variance (Tab. 3). When analyzed by the signed rank test (Snedecor and Cochran 1967), the trend for top and bottom halves to retain more total radioactivity than upright halves was significant $(P \leq 0.05)$ at the $2-$ and $4 \mathrm{~h}$ harvests for $\left[{ }^{3} \mathrm{H}\right]-\mathrm{GA}_{1}$-fed plants.

The decreased leakiness in gravistimulated stem segments could speculatively be attributed to an increased availability fo GA/GA metabolite binding sites in cells that are expanding in response to gravistimulation. Further studies, probably with intact plants, will be necessary to trace the early and long-term kinetics of free GAs and GA conjugate levels in the oat shoot pulvini after gravistimulation.

In an earlier report (Pharis et al. 1981) using intact plants, top halves had apparently conjugated $\left[{ }^{3} \mathrm{H}\right]-\mathrm{GA}_{4}$ and its free GA metabolites to a much greater extent than had bottom halves or vertical halves. However, this earlier report dealt with effects occurring over $48 \mathrm{~h}$ (to a $30^{\circ}$ curvature) after initial gravistimulation of the intact plants. In the present work (Tab. 3) one can also calculate the conjugate-like radioactivity for each stem segment balf as a percentage of the total radioactivity present in that half. Thus, top halves $>$ bottom halves $>$ vertical halves $(65 \%>63 \%>60 \%)$ in percentage of conjugate present for $\left[{ }^{3} \mathrm{H}\right]-\mathrm{GA}_{\mathrm{I}}$-fed plants after $1 \mathrm{~h}$ of gravistimulation. Similarly, one can compare top halves of $\left[{ }^{3} \mathrm{H}\right]-\mathrm{GA}_{1}$-fed plants with vertical halves after $2 \mathrm{~h}$ of geostimulation (top halves > vertical halves; $73 \%$ $>66 \%$ conjugate). However, these differences are not statistically significant, and by hour 4 of gravistimulation the tendency to have a higher percentage of conjugate in top halves did not occur. The $\left[{ }^{3} \mathrm{H}\right]-\mathrm{GA}_{4}$-fed plants had approximately $80+\%$ of their radioactivity in conjugate at all harvests $(1,2$ and 4 h after gravistimulation) and no consistent tendency occurred in the proportion of conjugate in the various stem segment parts.

Thus, the tendency for greater conjugation by top halves of $\left[{ }^{3} \mathrm{H}\right]-\mathrm{GA}_{4}$-fed intact plants shown over $48 \mathrm{~h}$ of gravistimulation by Pharis et al. (1981) was apparent only for $\left[{ }^{3} \mathrm{H}\right]-\mathrm{GA}_{1}$-fed plants in the present work (Tab. 3 ), and there only at harvests 1 and $2 \mathrm{~h}$ after gravistimulation. The lack of a consistent trend over all harvests, and for both GAs, may be caused by (1) the very high level of conjugate already existing at the time of gravistimulation, or (2) the short gravistimulation periods (e.g. reversible conjugation was apparently not a major factor, and trends (if present) in de novo conjugation could not be seen due to the high background of already existing conjugate). Additionally, the "leakiness" problem inherent in the use of excised segments may have confounded any trends in conjugation if differential solubility of free GAs and GA conjugates exists.

\section{References}

Bandurski, R., Schulze, A., Dayanandan, P \& Kaufman, P. B. 1984. Changes in free IAA in relation to asymmetric growth in Zea Mays seedlings. - Plant Physiol. 74: 284-288.

Beyer, E. M. 1976. A potent inhibitor of ethylene action in plants. - Plant Physiol. 58: 268-271

Blake, T. J., Pharis, R. P. \& Reid, D. M. 1980 . Ethylene, gibberellins, and auxin and the apical control of branch angle in a conifer, Cupressus arizonica. - Planta 150: 64-68.

Bucher, D. \& Pilet, P. E. 1981. Ethylene production in growing and gravireacting maize and pea root segments. - Plant Sci. Lett. 22: 7-11.

Clifford, P. E., Reid, D. M. \& Pharis, R. P. 1983 . Endogenous ethylene coes not initiate but may modify geobending - a role of ethylene in andotropism. - Plant Cell Environ. 6: $433-436$.

Durley, R. C., Crozier, A., Pharis, R. P. \& McLaughlin, G. E. 1972. Chromatography of 33 gibberellins on a gradient-eluted silica gel partition colwmn. - Phytochemistry 11: 3029 3033.

Huxter, T. J., Reid, D. M. \& Thorpe, T. A. 1979. Ethylene production by tobacco (Nicotiana tabacum) callus. - Physiol. Plant. 46: 374-380.

Kaufman, P. B., Ghosheh, N. S., Nakosteen, L., Pharis, R. P., Durley, R. C. \& Morf, W. 1976. Analysis of native gibberellins in the internode, node, leaves and inflorescence in developing Avena plants. - Plant Physiol. 58: 131-134.

- , Bandurski, R., Dayanandan, P., Koning, R. \& Harrison, M. 1979. Hormonal regulation of the megative geotropic response in Avena shoots. - Plant Physiol. 63: (Suppl.) 143.

- \& Dayanandan, P. 1984. Hormonal regulation of the gravitropic curvature response in cereal grass shoots. - In Hormonal Regulation of Plant Growth Processes (S. S. Purohit, ed.), Vol. I, pp. 369-385.

Koshioka, M., Takeno, K., Beall, F. D. \& Pharis, R. P. 1983. Purification and separation of plant gibberellins from their precursors and glucosyl conjugates. - Plant Physiol. 73: $398-406$.

Patil, S. S. \& Tang, C. S. 1974. Inhibition of ethylene evolution in papaya pulp tissue by benzyl isothiocyanate. - Plant Physiol. 48: 1-4.

Pharis, R. P., Legge, R. L., Noma, M., Kaufman, P. R., Ghosheh, N. S., LaCroix, J. D. \& Heller, K. 1981. Changes in endogenous gibberellins and the metabolism of $\left[{ }^{3} \mathrm{H}\right]-\mathrm{GA}_{4}$ after geostimulation in shoots of the oat plant (Avena sativa). - Plant Physiol. 67: 892-897.

Robert, M. L., Taylor, M. F. \& Wain, R. L. 1975. Ethylene production by cress roots and excised root segments and its inhibition by 3,5-diiodo-L-hydroxybenzoic acid. - Planta 125: $273-284$ 
Salisbury, F. B. \& Wheeler, R. M. 1981. Interpreting plant responses to clinostating. I. Mechanical stresses and ethylene. - Plant Physiol. 67: 677-685.

Snedecor, G. W. \& Cochran, W. G. 1967. Statistical Methods (6th Edl.). - Iowa State University Press, Ames, Iowa, pp. 128-130.

Wheeler, R. M. \& Salisbury, F. B. 1981. Gravitropism in higher plant shoots. 1 A role for ethylene. - Plant Physiol. 67: $686-690$.

Wright, M., Mousdale, D. M. A. \& Osborne, D. J. 1978. Evidence for a gravity-regulated level of endogenous auxin controlling cell elongation and ethylene production during gravitropic bending in grass nodes. - Biochem. Physiol. Pflanz. 172: 581-596. 
This document is a scanned copy of a printed document. No warranty is given about the accuracy of the copy. Users should refer to the original published version of the material. 